\title{
Manufacturing and Evaluation of Mechanical, Morphological, and Thermal Properties of Reduced Graphene Oxide-Reinforced Expanded Polystyrene (EPS) Nanocomposites
}

\author{
Tomasz Rydzkowski (D, ${ }^{1}$ Kazimierz Reszka, ${ }^{2}$ Mieczysław Szczypiński, ${ }^{1,3}$ \\ Michał Marek Szczypiński, ${ }^{3,4}$ Elżbieta Kopczyńska, ${ }^{1,3,5}$ and Vijay Kumar Thakur $\mathbb{D}^{6,7}$ \\ ${ }^{1}$ Faculty of Mechanical Engineering, Koszalin University of Technology, Raclawicka 15-17, Koszalin 75-620, Poland \\ ${ }^{2}$ Division of Materials Science and Technical Ceramics, Koszalin University of Technology, Śniadeckich Str. 2, \\ Koszalin 75-453, Poland \\ ${ }^{3}$ Termex Sp. $z$ o.o. Lniana 9, Koszalin 75-213, Poland \\ ${ }^{4}$ Department of Material Science, Faculty of Mechanical Engineering, Technical University of Liberec, Studentská 2, \\ Liberec 461 17, Czech Republic \\ ${ }^{5}$ Faculty of Technology and Education, Koszalin University of Technology, Śniadeckich 2, Koszalin 75-453, Poland \\ ${ }^{6}$ Biorefining and Advanced Materials Research Center, Department of Engineering, Science and Technology, \\ Scotland's Rural College (SRUC), Kings Buildings, West Mains Road, Edinburgh EH9 3JG, UK \\ ${ }^{7}$ Department of Mechanical Engineering, School of Engineering, Shiv Nadar University, Uttar Pradesh 201314, India
}

Correspondence should be addressed to Vijay Kumar Thakur; vijayisu@hotmail.com

Received 17 November 2019; Revised 31 January 2020; Accepted 3 March 2020; Published 25 April 2020

Academic Editor: Kinga Pielichowska

Copyright (c) 2020 Tomasz Rydzkowski et al. This is an open access article distributed under the Creative Commons Attribution License, which permits unrestricted use, distribution, and reproduction in any medium, provided the original work is properly cited.

\begin{abstract}
The aim of the present study is to examine the effect of the addition of carbon nanoparticles ( $\sigma \mathrm{sp}^{2}$ hybridization) on the mechanical properties of foamed polystyrene. In this work, we focus on the study of the impact of compressive stress, tensile strength, bending strength, thermal conductivity ratio $(\lambda)$, and water absorption of expanded polystyrene (EPS) reinforced with reduced graphene oxide and graphite. The results were compared with pristine EPS and reduced graphene oxidereinforced EPS. All the nanocomposite specimens used for testing had a similar density. The study reveals that the nanocomposites exhibit different thermal conductivities and mechanical properties in comparison to pristine EPS. The enhancement in the properties of the nanocomposite could be associated with a more extensive structure of elementary cells of expanded polystyrene granules.
\end{abstract}

\section{Introduction}

Amorphous polystyrene (PS) is a transparent material characterized by good tensile strength, up to $60 \mathrm{MPa}$, low impact strength, $2 \mathrm{~kJ} / \mathrm{m}^{2}$, medium hardness, and good dielectric properties, breakdown voltage up to $65 \mathrm{kV} / \mathrm{mm}$ $[1,2]$. It is resistant to acids (excluding concentrated and oxidizing), alcohols, alkalis, fats, and oils, making it a good material for a number of commodity applications $[3,4]$. One of the biggest advantages of PS is its softening temperature that is lower than that of other polyolefins, such as polypropylene and polyethylene, which are frequently used in the injection molding technology as well as in other manufacturing techniques $[5,6]$. It also retains its physical and mechanical properties for repeated processing $[3,7]$. Due to its insulating properties, it is used as an insulating material in the electrical and electronic industry, as well as for the production of films and optical products due to a high refractive index, $n 1.596 \div 1.593$. Polystyrene is a product of styrene liquid polymerization, which readily polymerizes 
under the influence of temperature and light, in the presence of oxygen in the atmosphere $[8,9]$. As far as industrial methods are concerned, solution polymerization has limited application because the polymer with the lowest molecular weight is obtained. On the other hand, emulsion polymerization is mainly carried out to obtain styrene copolymers with other vinyl monomers [10]. However, suspension polymerization gives the least unreacted monomer in production and is free from most of the disadvantages that occur in bulk polymerization, which requires the presence of radical initiators [11]. Polystyrene enriched with foaming agents is applicable to the production of expanded polystyrene (EPS) [12-14], with cellular structure. Polystyrene in the form of beads containing foaming agents is obtained in the suspension polymerization of styrene with the addition of blowing agents or low boiling liquids, e.g., pentane, butane, or propane $[15,16]$. Depending on the purpose and the polymerization conditions, beads of various sizes (from $0.3-2.5 \mathrm{~mm}$ ) are obtained. In this process, in addition to the basic monomer of styrene, the other monomers, such as acrylonitrile, are used, which increases the chemical resistance of expanded products, as well as flame retardants characteristics [17]. As far as flame retardants are considered, the addition of clay minerals with a montmorillonite and attapulgite structure may be used as well in order to improve mechanical properties and reduce thermal conductivity at the granule formation stage [18]. Modifiers in the form of organic or inorganic additives with the different morphological structures are added, thus forming a foam composite material in which the dispersed phase is located in the structure of polystyrene walls or nanoparticles of additives are suspended in the cellular space of the foam structure [19]. Among others, graphite (in the form of dust) has been used. Its presence in the walls of the expanded polystyrene (EPS) cell structure affects the limitation of the heat flow [13].

Allotropic varieties of carbon are widely used in numerous applications related to energy, among others in solar energy [20-22]. In this study, we present research results on the selected mechanical, physical, and thermal properties of expanded polystyrene EPS and EPS with two share addition of reduced graphene oxide (EGO) and with the addition of graphite nanoparticles (EG). Composites with reduced graphene oxide nanoparticles were coated at the preexpansion stage, and composites with graphite nanoparticles have been mixed with graphite at the granule formation stage. Water absorption tests and measurement of the thermal conductivity measurements were also carried out. Reduced graphene oxide was used because of structural affinity with graphite, low polarity (increases the affinity for nonpolar polystyrene), and its relatively low cytotoxicity (in case of direct skin contact) $[23,24]$ and good absorption of IR wavelength [25].

\section{Experiment}

In this work, the main technological task was to develop a method for depositing nanoparticles of reduced graphene oxide onto the surfaces of preexpanded polystyrene granules, followed by block formation. For this purpose, reduced graphene oxide with a composition of $\mathrm{C}>85 \%, \mathrm{O}<10 \%, \mathrm{H}$ $<1 \%, \mathrm{~N}<3 \%$, sulphates, $\mathrm{MgO}<0.1 \%$, and ash $<1 \%$, manufactured by NANOMATERIALS LS, Poland, was used. Two suspension compositions were prepared, consisting of alcohol and reduced graphene oxide, with the proportions presented in Table 1. The reduced graphene oxide dispersion in isopropyl alcohol (IPA) was prepared using an ultrasonic homogenizer in order to better disperse the particles and avoid their reaggregation. The choice of IPA as a dispersion medium was not accidental. The low polarity of IPA allows for proper mixing with nanoparticles of reduced graphene oxide (avoiding sedimentation) and good wetting of the surface of EPS granules. Due to this, the proper adhesion of graphene particles to EPS granules after solvent evaporation is obtained. The suspensions were spread over the surface of the granules using a high-speed rotary mixer in three directions.

EPS without additives are marked with the symbol $\mathrm{E}$ and EPS with the addition of graphite, EG.

In order to manufacture EPS blocks, preexpanded granules with following densities were used: $18.5 \mathrm{~g} / \mathrm{cm}^{3}$ in the case of EPS without additives, $18.8 \mathrm{~g} / \mathrm{cm}^{3}$ in the case of graphite composite, and $18.5 \mathrm{~g} / \mathrm{cm}^{3}$ in the case of composite with reduced graphene oxide. EPS with graphite (EG) sections are characterized by visible EPS balls with a larger diameter; this is due to the fact that they were made of PS granules with different (bigger) granulation. Graphite was introduced into the PS during the production of such granules. All tested samples E, EG, and EGO had similar densities.

The cellular structure of expanded polystyrene and the distribution of graphite particles and reduced graphene oxide in the structure of expanded granules were examined on cross sections using a JEOL 5500LV scanning electron microscope under environmental conditions. The tests were carried out on $1 \div 2 \mathrm{~mm}$ thick sections. The study of mechanical properties has been focused on bending strength (until the break), tensile strength, and compressive strength (to obtain a deformation corresponding to $10 \%$ of the dimension value according to the compression direction).

The experimental EPS blocks with dimensions $0.25 \times 0.25 \times 0.25 \mathrm{~m}$ were formed. The blocks were sliced into 5 boards, $50 \mathrm{~mm}$ thick. From these boards were the test samples cut, according to Figure 1. From each block, we cut out 7 samples. The place where the test samples were taken is marked in black.

The dimensions of the samples taken for testing are shown in Figure 2.

Water absorption tests applying the gravimetric method were also carried out. For this purpose, RADWAG's scale with the possibility of a continuous register of mass changes with an accuracy of $\Delta \mathrm{m}=10^{-5} \mathrm{~g}$ was used. Samples of $50 \times 55 \times 10 \mathrm{~mm}$ (Figure 3) were immersed to a depth of $80 \mathrm{~cm}$. Before immersion, they were placed in a vacuum desiccator for 20 minutes to pump out the air. In the desiccator, they were kept for $30 \mathrm{~min}$ after reducing the vacuum with argon to atmospheric pressure.

The thermal properties were tested in accordance with the standard PN-EN 12939:2002 [8]. For the purpose of test, a set of 70 panel samples $300 \times 300 \times 50 \mathrm{~mm}$ was prepared. 
TABLE 1: Suspension compositions and proportions of reduced graphene oxide deposited on the surface of preexpanded polystyrene granules.

\begin{tabular}{lcc}
\hline Symbols of samples & EGO 1 & EGO 2 \\
\hline Graphene mass & $0.259 \mathrm{~g}$ & $0.462 \mathrm{~g}$ \\
Graphene + alcohol mass & $75.155 \mathrm{~g}$ & $75.443 \mathrm{~g}$ \\
Part of reduced graphene oxide in EPS & $0.089 \%$ by weight & $0.146 \%$ by weight \\
\hline
\end{tabular}
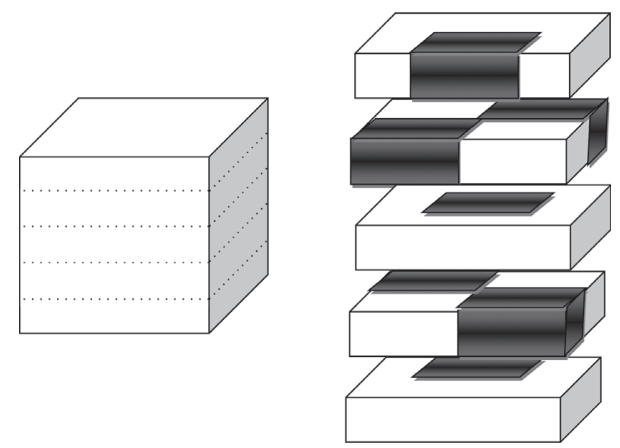

FIGURE 1: The scheme of cutting the block into boards with marking the places of material sampling.

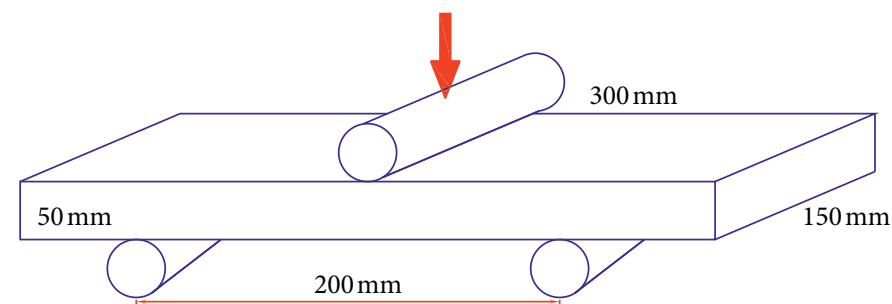

(a)

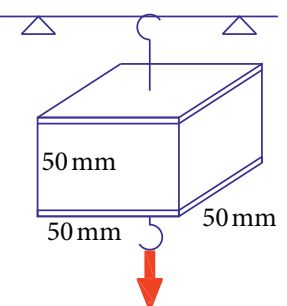

(b)

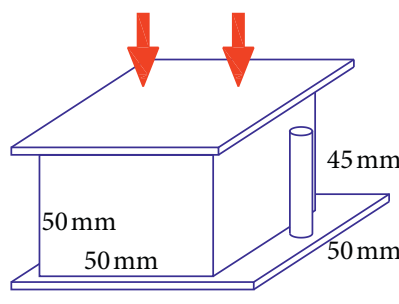

(c)

Figure 2: The dimensions of the samples taken for testing: (a) bending strength, (b) tensile strength, and (c) compressive strength (45 mm limiter allows obtaining the same deformation up to $10 \%$ of the initial dimension); the areas where the load is applied are marked with arrows.

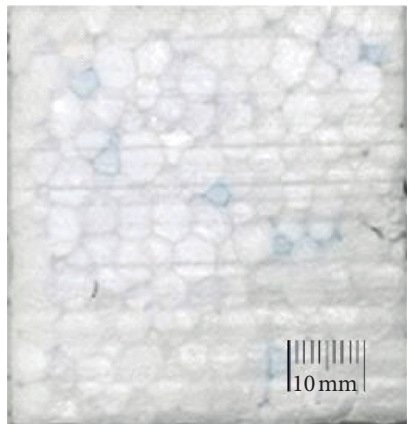

(a)

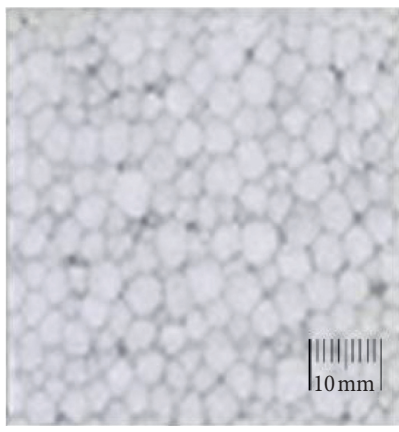

(b)

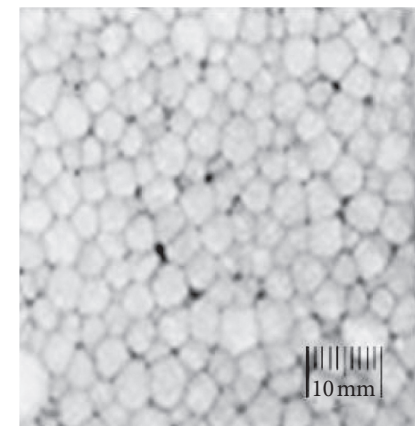

(c)

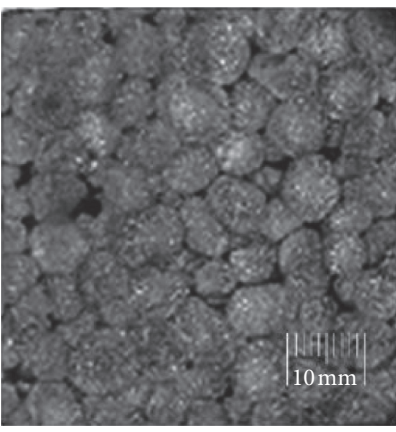

(d)

FIgURE 3: Photographic images of the cross-sectional area of samples that were tested for water absorption: (a) without additives E, (b) with the addition of reduced graphene oxide (EGO1), (c) with the addition of reduced graphene oxide (EGO2), and (d) with the addition of graphite (EG).

The panels were stored in a climate chamber at $23^{\circ} \mathrm{C}$ and $50 \%$ humidity. The samples were then dried in a laboratory dryer at $70^{\circ} \mathrm{C}$ until the weight of each sample was stabilized. The thermal conductivity index $\lambda$ was determined using the NETZSCH HFM 436 device and the Proteus 70 software.

\section{Results and Discussion}

3.1. Deposition of Reduced Graphene Oxide Nanoparticles. The photographs of preexpanded granules shown in Figure 4 display that there is a clear optical difference relative to the 
uncoated granules (Figure 4(a)) consisting of the darkening of the granules resulting from their coating with reduced graphene oxide particles (Figures 4(b) and 4(c)).

It should also be noted that a small difference in the proportion of reduced graphene oxide between GO1 and GO2 samples of $0.057 \%$ by weight exhibited noticeably greater darkening of GO2 samples. This may indicate welldispersed reduced graphene oxide particles in suspension and good dispersal of particles on the surface of the granules as a result of rotational mixing in three directions.

\subsection{Distribution of Graphite and Reduced Graphene Oxide} Nanoparticles in the Cellular Structure of Composites. The scanning electron microscope examinations of specimens' cross sections have shown that the expandable polystyrene foam structure (E) is made of cells separated by polymer walls whose thickness does not exceed $5 \mu \mathrm{m}$ (Figure 5(a)). The cells compressed during foaming were formed within the surface of the granules under the influence of the blowing agent (Figure 5(b)). In the granules bonding zones, the cells are smaller and heavily deflected as a result of the resistance that arises between them during swelling. At the interface of several granules, empty spaces arise in which quantity and size affect the strength and water absorption of the material.

Investigations of the polymer-graphite composites (EG) have shown that the nanoparticles and graphite particles introduced into the granules during their formation, in the final foaming process, form an integral structure of the cell walls in which they are dispersed in a uniform manner (Figure 6(a)). There was no concentration of graphite particles in the contact zone between foamed granules. Large free space was found between granules than in pure EPS (E). The deformation of the cells in the contact area between the granules is also smaller which may affect the weaker connection between them (Figure 6(b)).

In the case of EPS-reduced graphene oxide composites, microscopic observations showed that the process of expanding the granules to the final state caused the dislocation of particles on the surface and significantly reduced the density of their arrangement. This is assessed on the basis of the distribution of reduced graphene oxide particles in the contact zone of granules (Figure $7(\mathrm{a})$ ) because the cross section through this zone determines the circumferences of the two granules connected at this point. The presence of reduced graphene oxide particles inside cells is sporadic and may result from mechanical shifting from the surface zone to the nearest formed cells (Figure 7(b)).

The graphene nanoparticles are clearly visible in the granule bonding zone. The presence of particles between granules in a state of high surface scattering makes it possible to equate this to a spheroidal system (Figure 8), where the nanoparticles form a denser coating, although they are not microscopically identified. However, microscopically identifiable particles occur less frequently and their arrangement is accidental.

3.3. Bending Strength Test. The results of studies on the influence of additives in the form of graphite particles and reduced graphene oxide on bending strength show that the foam composite of polystyrene with graphite has the weakest properties. In relation to polystyrene without additives (sample E), the introduction of reduced graphene oxide into the structure of particles caused the improvement in the properties, especially in the case of EGO2 samples containing a larger amount of reduced graphene oxide additive.

Reduction of the bending strength of the composites with graphite in relation to pure EPS can be associated with the process of dispersion of graphite layers with the participation of polystyrene at the granule formation stage (Figure 9). In the further foaming process, this condition occurs in the cell walls and may contribute to their weakening. Under the influence of pressure, they are likely to be damaged more easily, which translates into worse endurance results. An additional factor that weakens the strength parameters is the porosity occurring within the graphite grains [8].

3.4. Tensile Strength Test. The comparison of results shows that, in this test, the worst results were obtained for polystyrene without modifiers (Figure 10).

Probably, the surface effects of the interactions of granules between the additive particles, which may introduce pseudoreinforcements on the micrometer scale of the polymeric material, determine this. They are particularly strong in the case of reduced graphene oxide particles in which there is no such easy division of layers as in the case of graphite. Consideration should be given to the fact that, on pellets there exist pseudocoatings of nanoparticles that interact with each other directly or through the nanofilms of polystyrene under counteracting forces (Figure 11). Therefore, the developed nanocomposite with reduced graphene oxide has the highest tensile strength.

Numerous studies present the impact of nanoparticles on the strength properties of polymer composites. In the case of exfoliating nanoparticles, a negative impact on strength properties was also sometimes found. CzarneckaKomorowska and Sterzyński studied the addition of polyhedral oligomeric silsesquioxane (POSS) nanoparticles' effects on the structure and changes in strength and thermomechanical properties of polymer POM composites. Polyhedral oligomeric silsesquioxane (POSS) particles may be taken as a nucleating agent. The addition of POSS nanoparticles increased their degree of crystallinity, resulting in changes in the mechanical properties of composites, e.g., in improved strength and reduced flexibility. An increase in the degree of crystallinity resulted in an increase in maximum melting temperature and melting enthalpy. Of course, these effects depend on the amount of additive introduced [26-29]. We have not conducted such structure and thermal properties studies yet; we plan to implement them in the near future.

3.5. Compressive Strength Test. Compressive strength tests carried out for 6 samples from each series showed that the least durable material is the pristine EPS; the compressive stress was determined at $70 \mathrm{kPa}$, sample E (Figure 12). The 


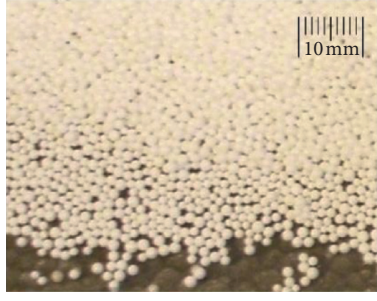

(a)

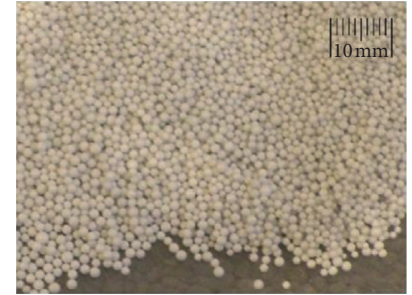

(b)

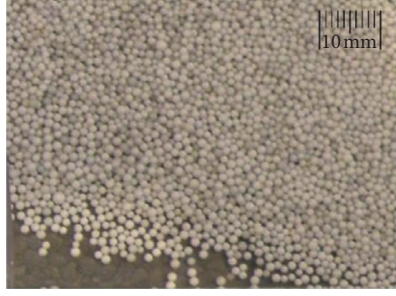

(c)

Figure 4: View of preexpanded granules: (a) without deposited particles of reduced graphene oxide E, (b) with the content of 0.089 wt $\%$ (GO1), and (c) with $0.146 \mathrm{wt} \%(\mathrm{GO} 2)$.

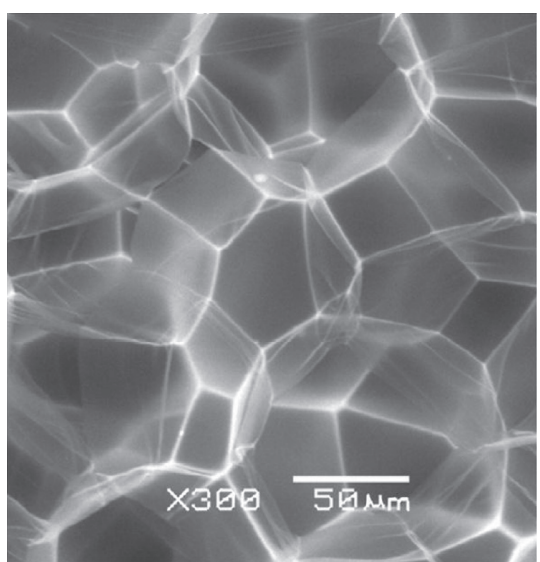

(a)

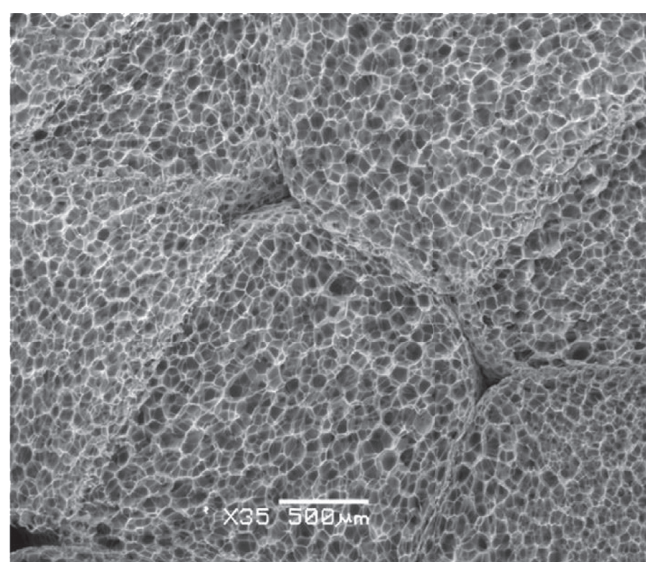

(b)

Figure 5: Cross section through a sample of expanded polystyrene: (a) thin-walled cell structure without additional modifying fillers. (b) The structure of expanded granules with zones of cell compression at their bonding points and empty spaces at the interface of several granules.

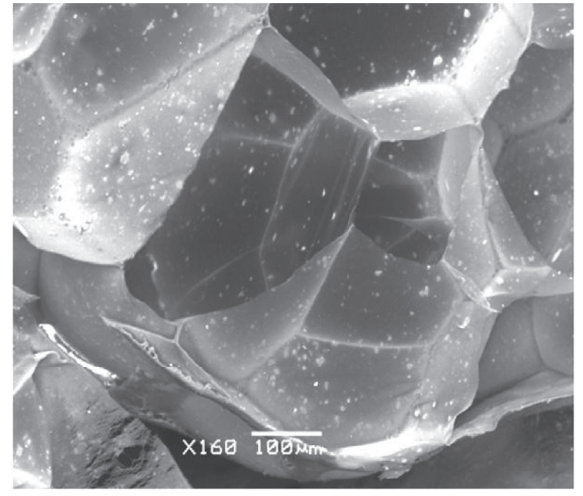

(a)

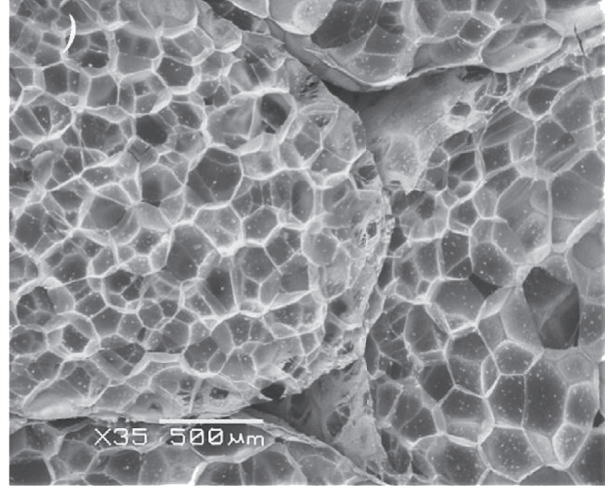

(b)

Figure 6: Cross section through a sample from an expanded polystyrene-graphite composite (EG): (a) a view of cellular structures made of thin polymer walls containing graphite particles and nanoparticles, and (b) the place of connection of several expanded granules with void spaces; there is no crumple zone of cells at the boundaries of granules.

slightly poorer parameters showed polystyrene with graphite, approx. $80 \mathrm{kPa}$. However, the highest compressive strength was obtained for a composite with reduced graphene oxide, above $100 \mathrm{kPa}$.

If it is assumed that the polystyrene bubbles solidified after foaming are equivalents of grains, the mechanism of polystyrene strengthening, expressed by the improvement of some of its mechanical properties, can be compared to the strengthening created as a result of precipitations at intergrains boundaries in metals. Such results were obtained by Wang [30]. The influence of precipitations within the grain boundaries on the increase in hardness was also 


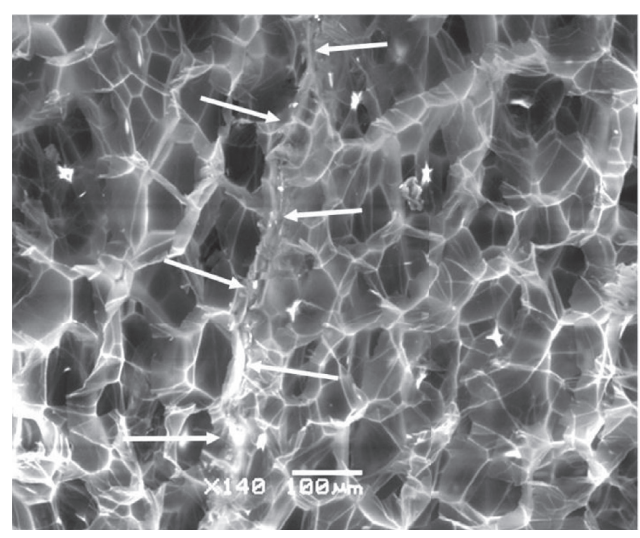

(a)

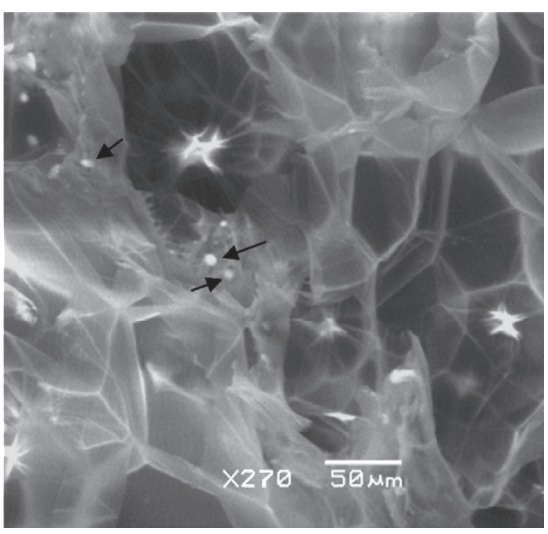

(b)

Figure 7: Cross section through a sample of expanded polystyrene-reduced graphene oxide (EGO) composite: (a) a fragment of the connection zone between the granules and particles of reduced graphene oxide located along this zone (marked with arrows). (b) View of cellular structures made of thin walls and thin-walled mineral flame retardants.

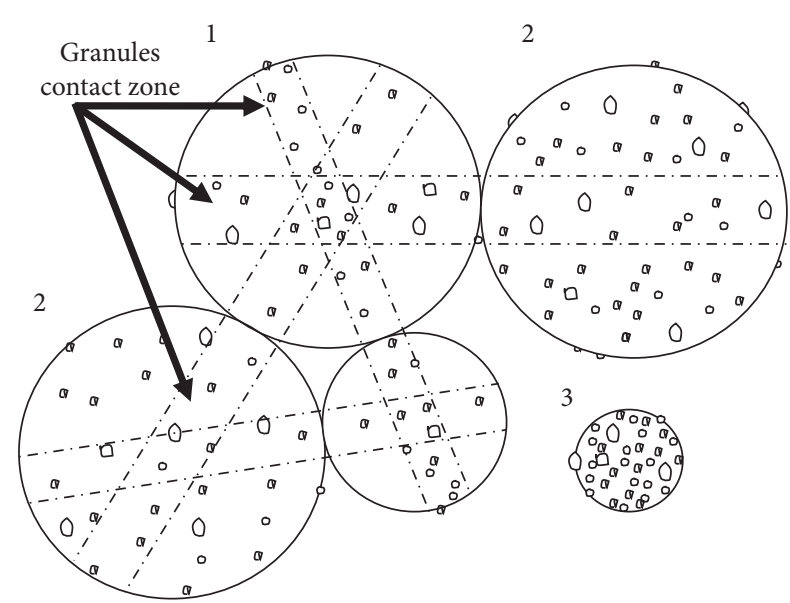

FIGURE 8: The spheroidal model of reduced graphene oxide particles transfer on the surface of granules as a result of contact with other granules: 1 , a schematic representation of the zone of mutual contact with an adjacent granule; 2 , a schematic representation of the distribution of nanoparticles on the surfaces of granules after expansion; 3, a schematic representation of the distribution of nanoparticles on the surfaces of granules before expansion.

demonstrated by Zheng, examining the corrosion properties of the Al-Mg-Si alloy, depending on the Si content [31].

This can be explained by a similar mechanism of interactions of granules as in the case of a tensile test, especially in the initial compression phase. It cannot be ruled out; however, the effect of compacting additives during compression, especially in the case of graphene oxide, which may additionally result in the process of hardening the material and increasing the pressure force to obtain the same deformation as in the other samples.

3.6. Thermal Conductivity Test. A comparative study of the thermal conductivity coefficient $(\lambda)$ is shown in the diagram (Figure 13). The comparison shows that the best insulating

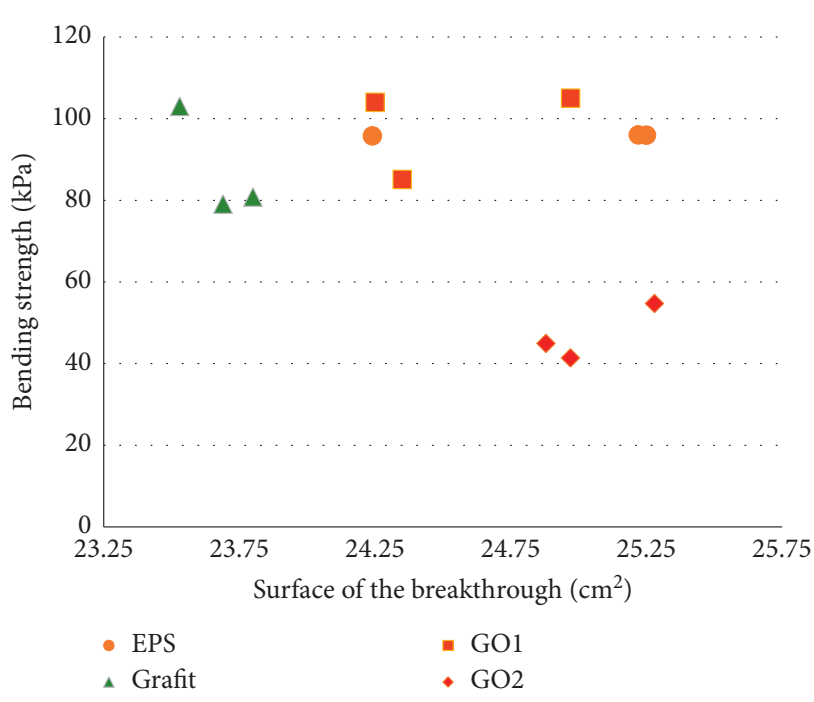

FIGURE 9: Bending strength perpendicular to the front face for pure EPS (sample E) doped with reduced graphene oxide (samples EGO1 and EGO2) and graphite nanoparticles (sample EG).

properties have been found for a nanocomposite foam with the addition of graphite because it has the lowest $\lambda$ coefficient ranging from 0.024 to $0.025 \mathrm{~W} / \mathrm{mK}$. The pure EPS (E) shows a $\lambda$ coefficient slightly below $0.04 \mathrm{~W} / \mathrm{mK}$. Composites with the addition of reduced graphene oxide showed a thermal conductivity similar to the series (E). Lakos showed that the thermal conductivity of gray EPS, doped with graphite, is less than pure EPS. He also showed that lambda changes, that occur under the influence of moisture, are greater for gray EPS, but the thermal conductivity remains smaller over time compared to others $[32,33]$.

The reduction of thermal conductivity through additives can be explained by the process of heat dissipation on their particles. In the case of a graphite composite, scattering occurs in the volume of the material because the particles contained in it act as micromirrors reflecting thermal radiation in different directions and as a result its dissipation. 


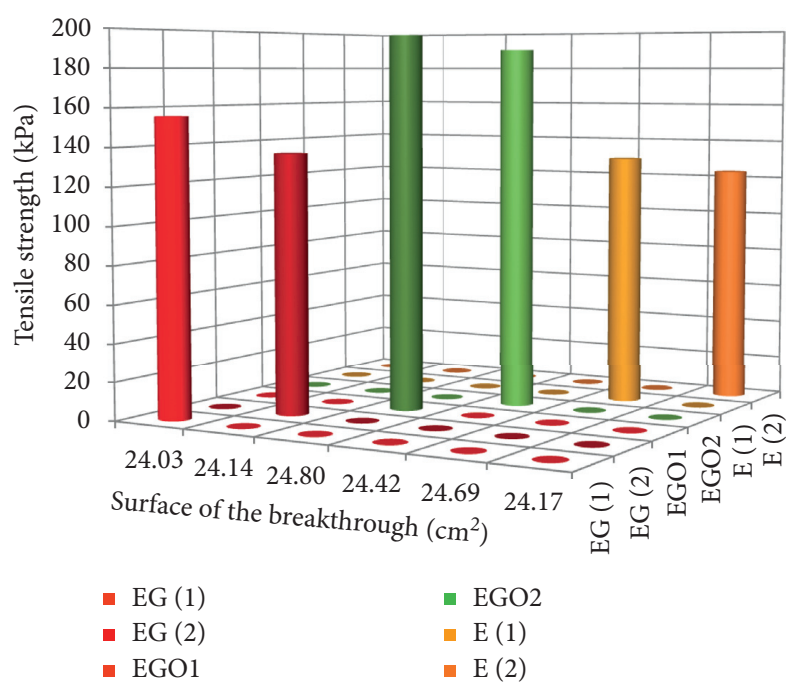

FIgURE 10: Comparison of tensile strength for pure EPS (E) doped with reduced graphene oxide (EGO 1 and EGO 2) and graphite (EG) nanoparticles. In the case of E specimens and EG specimens, average results obtained with two groups are presented.

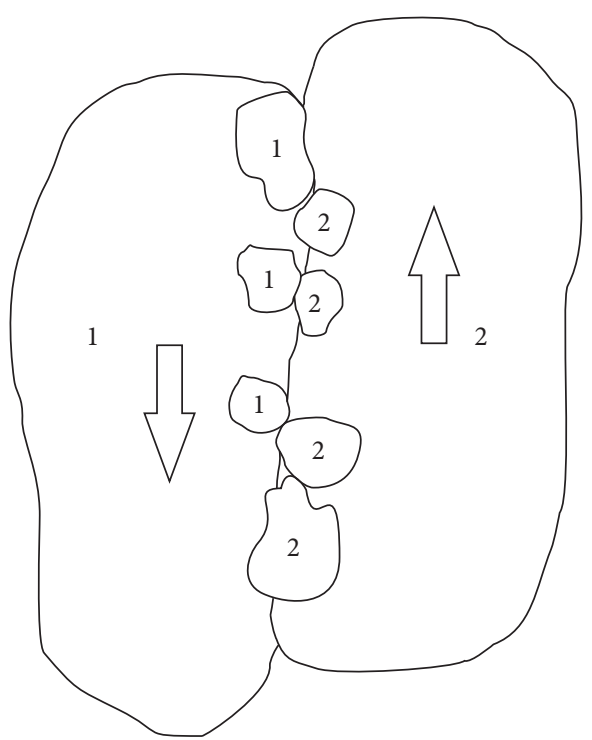

FIGURE 11: Diagram of the interaction of two granules, which are affected by opposite forces during the tensile test. The digits indicate the nanoparticles located in the connection zone belonging to the respective granules.

An example of a micromirror is the product described in the work of Janglong Zhang [34]. This is of course a completely different product from graphene microparticles. However, it can be assumed that the mechanism of reflection of thermal radiation is similar in both cases. If the study found that the thermal conductivity of gray EPS (graphenedoped) is less than pure EPS and similar results were obtained for graphite-doped EPS, it is likely to assume that, after obtaining sufficiently high temperature through graphene particles, a further increase in the temperature of these particles due to poor thermal conductivity is difficult.

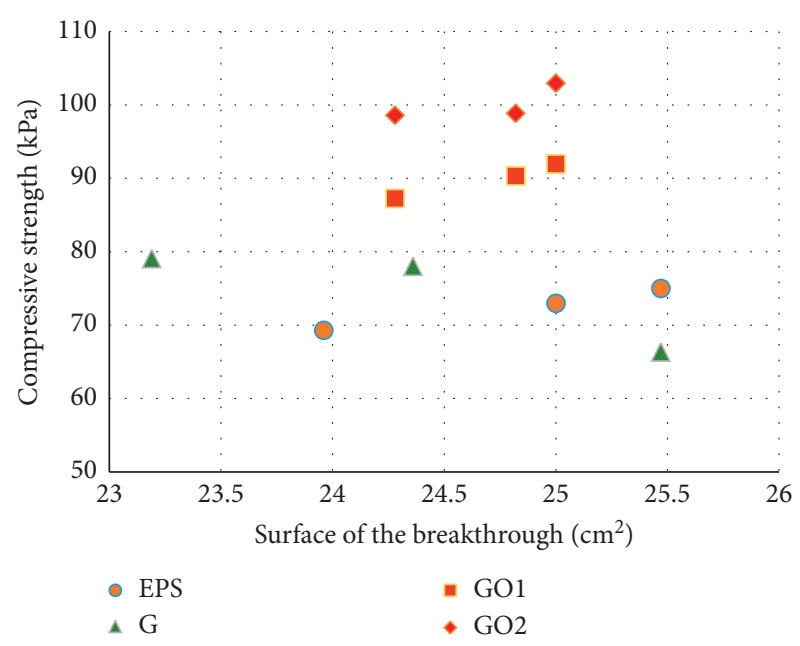

FIgURE 12: Comparison of compressive strength in $10 \%$ deformation, for pure EPS doped with reduced graphene oxide and graphite nanoparticles.

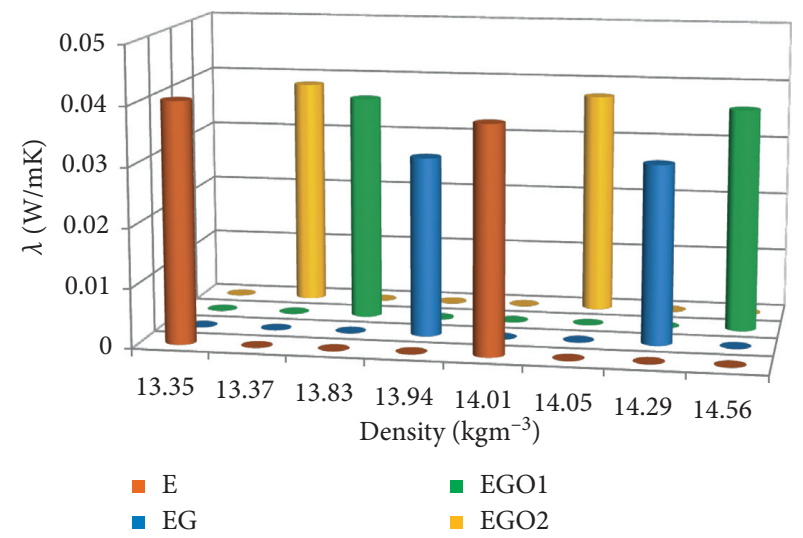

FIGURE 13: Comparison of thermal conductivity coefficient for pure EPS doped with reduced graphene oxide and graphite nanoparticles.

Thus, the heat stream reaching them will not be absorbed in the time unit, but reflected or diffused. Hypothetically, it can be assumed that graphene microparticles affect the heat stream reaching them as micromirrors reflecting this radiation.

In the case of a composite with reduced graphene oxide, only the boundaries of granules can occur to dissipate thermal rays; hence, the effectiveness of this is small. The aforementioned mechanisms have only an additional effect because the main factors of thermal insulation are spaces in granulated cells, filled with air.

3.7. Water Absorption Test. Water absorbency tests showed that the nanocomposite with the addition of reduced graphene oxide (EGO2) showed the lowest total absorbability and the dynamics were small. Due to the low polarity of the reduced graphene oxide particles on the surface, the wettability of the polar medium, i.e., water, is reduced. This improves the hydrophilic properties of the obtained 


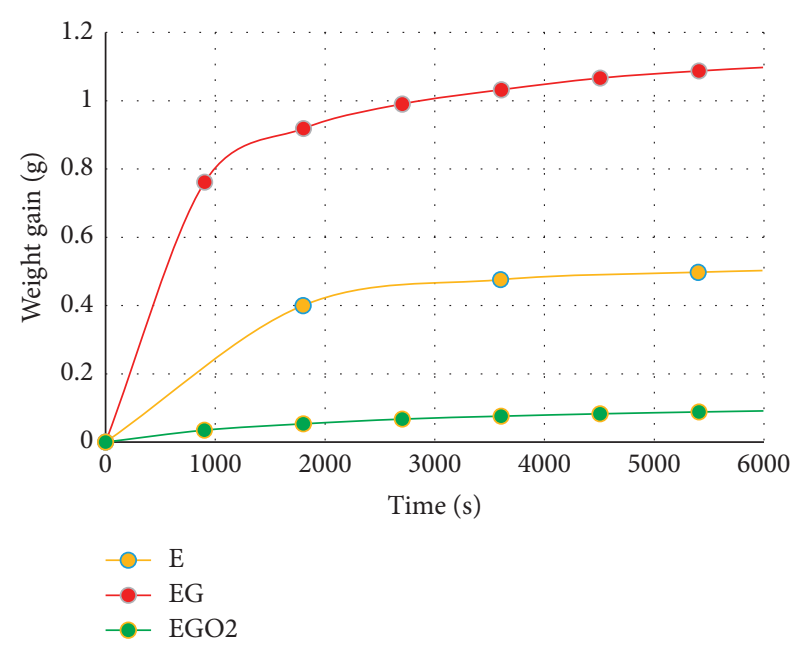

FIGURE 14: Water absorption for pure EPS (E), with the addition of reduced graphene oxide (EGO2) and graphite (EG).

composite compared to unmodified polystyrene. Due to the hydrophilic properties of the material, water penetration into the formed block is significantly inhibited, which results in a decrease in water absorption. In contrast, the nanocomposite with the addition of graphite showed the highest total absorbability and was characterized by high dynamics in the first period lasting about 1200 s. Against the background of the presented materials, the sorption properties of polystyrene without additives showed indirect water sorption properties (Figure 14).

The presence of reduced graphene oxide on the surface of the granules effectively blocked water penetration due to its hydrophobic character. In the case of a graphite composite, its high sorptivity is probably influenced by the porous structure of graphite particles and its surface properties. Low graphite wettability could be modified (enhanced) by the presence of functional groups on its surface (i.e., $-\mathrm{OH}$ and $-\mathrm{COOH}$ ), but to prove it, the XPS analysis should be made. Unfortunately, we do not have such results at the moment; such tests will be carried out soon and will explain our observations.

\section{Conclusion}

(1) The addition of reduced graphene oxide in the form of an alcohol suspension to the preexpanded polystyrene granules causes its good distribution at the surface boundaries of the granules in the final product.

(2) Composites with a small amount of reduced graphene oxide $0.089 \mathrm{wt} \%$ and $0.146 \mathrm{wt} \%$ have a much higher bending strength in comparison to a graphite composite and about $10 \%$ better than an EPS nondoped.

(3) Compressive strength is comparable for pure EPS and EPS with the addition of graphite and is higher for EPS with the addition of reduced graphene oxide.
(4) In the case of tensile strength, pure EPS has a nearly $40 \%$ lower value relative to EPS with the addition of reduced graphene oxide. This is in line with literature data; addition of nanoparticles usually improves strength properties.

(5) The addition of reduced graphene oxide does not affect the reduction of thermal conductivity; the lambda coefficient is comparable with EPS. The best thermal insulation properties have been found for EPS with graphite.

(6) The presence of reduced graphene oxide in the structure of composites is effective in reducing water absorption, probably due to its hydrophobic character. Confirmation of this statement requires further research.

\section{Data Availability}

No data were used to support this study.

\section{Conflicts of Interest}

The authors declare that they have no conflicts of interest.

\section{References}

[1] B. Massoumi, M. Abbasian, R. Mohammad-Rezaei, A. Farnudiyan-Habibi, and M. Jaymand, "Polystyrene-modified novolac epoxy resin/clay nanocomposite: synthesis, and characterization," Polymers for Advanced Technologies, vol. 30, no. 6, pp. 1484-1492, 2019.

[2] V. K. Thakur, E. J. Tan, M.-F. Lin, and P. S. Lee, "Polystyrene grafted polyvinylidenefluoride copolymers with high capacitive performance," Polymer Chemistry, vol. 2, no. 9, pp. 2000-2009, 2011.

[3] S. Thakur, A. Verma, B. Sharma, J. Chaudhary, S. Tamulevicius, and V. K. Thakur, "Recent developments in recycling of polystyrene based plastics," Current Opinion in Green and Sustainable Chemistry, vol. 13, pp. 32-38, 2018.

[4] H. Kokubo, E. Nakazawa, and M. Watanabe, "Solid polymer electrolytes based on polystyrene-polyether block copolymers having branched ether structure," Polymers for Advanced Technologies, vol. 30, no. 3, pp. 736-742, 2019.

[5] S. P. Thomas, "Rheological and thermal studies of polystyrene calcium phosphate nanocomposites," Polymers for Advanced Technologies, vol. 30, no. 2, pp. 381-389, 2019.

[6] X. Zhang, Y. Tan, R. Chen, G. Zhang, and J. Qu, "Dimensional impact of nanofillers on the micromorphology and rheology of PP/PS composites under continuous elongation flow," Polymers for Advanced Technologies, vol. 29, pp. 2952-2962, 2018.

[7] Y. Kong, Y. Li, G. Hu et al., "Effects of polystyrene-bpoly(ethylene/propylene)- $b$-polystyrene compatibilizer on the recycled polypropylene and recycled high-impact polystyrene blends," Polymers for Advanced Technologies, vol. 29, no. 8, pp. 2344-2351, 2018.

[8] Z. Zhang, A. Mulyadi, X. Kuang et al., "Lignin-polystyrene composite foams through high internal phase emulsion polymerization," Polymer Engineering \& Science, vol. 59, no. 5, pp. 964-972, 2019. 
[9] J. Huang, Z. Zhao, T. Chen et al., "Preparation of highly dispersed expandable graphite/polystyrene composite foam via suspension polymerization with enhanced fire retardation," Carbon, vol. 146, pp. 503-512, 2019.

[10] V. K. Thakur and M. K. Thakur, "Recent advances in graft copolymerization and applications of chitosan: a review," ACS Sustainable Chemistry \& Engineering, vol. 2, no. 12, pp. 2637-2652, 2014.

[11] M. K. Thakur, V. K. Thakur, R. K. Gupta, and A. Pappu, "Synthesis and applications of biodegradable soy based graft copolymers: a review," ACS Sustainable Chemistry \& Engineering, vol. 4, no. 1, pp. 1-17, 2016.

[12] N. H. R. Sulong, S. A. S. Mustapa, and M. K. A. Rashid, "Application of expanded polystyrene (EPS) in buildings and constructions: a review," Journal of Applied Polymer Science, vol. 136, no. 20, p. 47529, 2019.

[13] J. H. Crandell, "Below-ground performance of rigid polystyrene foam insulation: review of effective thermal resistivity values used in ASCE standard 32-01-design and construction of frost-protected shallow foundations," Journal of Cold Regions Engineering, vol. 24, no. 2, pp. 35-53, 2010.

[14] R. E. Smith, J. M. Alcott, and M. H. Mazor, Next-Generation Thermal Insulation Challenges and Opportunities, pp. 119130, ASTM International, West Conshohocken, PA, USA, 2014.

[15] C. Okolieocha, D. Raps, K. Subramaniam, and V. Altstädt, "Microcellular to nanocellular polymer foams: progress (2004-2015) and future directions-a review," European Polymer Journal, vol. 73, pp. 500-519, 2015.

[16] B. Yuan, G. Wang, S. Bai, and P. Liu, "Preparation of halogenfree flame-retardant expandable polystyrene foam by suspension polymerization," Journal of Applied Polymer Science, vol. 136, no. 29, p. 47779, 2019.

[17] S. Li, J. Yang, Y. Shao, and J. Li, "Preparation and characterization of nature flake graphite/polystyrene beads with waste expanded polystyrene," Chemistry Letters, vol. 47, no. 8, pp. 1067-1070, 2018.

[18] Y. Wang, H. Jiang, J. Ni et al., "Study on the effect of PolyFR and its FR system on the flame retardancy and foaming behavior of polystyrene," RSC Advances, vol. 9, no. 1, pp. 192-205, 2019.

[19] A. Kausar, "Structure and properties of polyacrylonitrile/ polystyrene and carbon nanoparticle-based nanocomposite foams," Advanced Materials Science, vol. 19, pp. 5-20, 2019.

[20] Z. Li, X. Zhao, C. Huang, and X. Gong, "Recent advances in green fabrication of luminescent solar concentrators using nontoxic quantum dots as fluorophores," Journal of Materials Chemistry C, vol. 7, no. 40, pp. 12373-12387, 2019.

[21] Y. Li, P. Miao, W. Zhou, X. Gong, and X. Zhao, "N-doped carbon-dots for luminescent solar concentrators," Journal of Materials Chemistry A, vol. 5, no. 40, pp. 21452-21459, 2017.

[22] W. Ma, W. Li, R. Liu, M. Cao, X. Zhao, and X. Gong, "Carbon dots and AIE molecules for highly efficient tandem luminescent solar concentrators," Chemical Communications, vol. 55, no. 52, pp. 7486-7489, 2019.

[23] M. Pelin, L. Fusco, V. León et al., "Differential cytotoxic effects of graphene and graphene oxide on skin keratinocytes," Scientific Reports, vol. 7, p. 40572, 2017.

[24] K.-H. Liao, Y.-S. Lin, C. W. Macosko, and C. L. Haynes, "Cytotoxicity of graphene oxide and graphene in human erythrocytes and skin fibroblasts," ACS Applied Materials \& Interfaces, vol. 3, no. 7, pp. 2607-2615, 2011.
[25] D. Ma, X. Li, Y. Guo, and Y. Zeng, "Study on IR properties of reduced graphene oxide," IOP Conference Series: Earth and Environmental Science, vol. 108, Article ID 022019, 2018.

[26] D. Czarnecka-Komorowska, T. Sterzynski, and J. Andrzejewski, "Evaluation of structure and thermomechanical properties of polyoxymethylene modified with polyhedral oligomeric silsesquioxanes (POSS)," Przemysl Chemiczny, vol. 92, pp. 2129-2132, 2013.

[27] D. Czarnecka-Komorowska, T. Sterzynski, and M. Dutkiewicz, "Polyoxymethylene/polyhedral oligomeric silsesquioxane composites: processing, crystallization, morphology and thermo-mechanical behavior," International Polymer Processing, vol. 31, no. 5, pp. 598-606, 2016.

[28] D. Czarnecka-Komorowska and T. Sterzynski, "Effect of polyhedral oligomeric silsesquioxane on the melting, structure, and mechanical behavior of polyoxymethylene," Polymers, vol. 10, p. 203, 2018.

[29] Z. Pelzbauer and A. Galeski, "Growth rate and morphology of polyoxymethylene supermolecular structures," Journal of Polymer Science Part C: Polymer Symposia, vol. 38, no. 1, pp. 23-32, 2007.

[30] C. S. Wang, R. Q. Wang, Y. Wang, and Y. X. Fu, "Study on curing process of resin nanocomposites," Key Engineering Materials, vol. 501, pp. 349-354, 2012.

[31] Y. Zheng, B. Luo, Z. Bai, J. Wang, and Y. Yin, "Study of the precipitation hardening behaviour and intergranular corrosion of Al-Mg-Si alloys with differing Si contents," Metals, vol. 7, no. 10, p. 387, 2017.

[32] Á3 Lakatos and F. Kalmár, "Analysis of water sorption and thermal conductivity of expanded polystyrene insulation materials," Building Services Engineering Research and Technology, vol. 34, no. 4, pp. 407-416, 2013.

[33] Á3 Lakatos and F. Kalmár, "Investigation of thickness and density dependence of thermal conductivity of expanded polystyrene insulation materials," Materials and Structures, vol. 46, no. 7, pp. 1101-1105, 2013.

[34] J. Jianglong Zhang, Y.-C. Yung-Cheng Lee, A. Tuantranont, and V. M. Bright, "Thermal analysis of micromirrors for highenergy applications," IEEE Transactions on Advanced Packaging, vol. 26, no. 3, pp. 310-317, 2003. 